\title{
Meta-Ontology, Naturalism, and the Quine-Barcan Marcus Debate
}

\section{Document Version}

Accepted author manuscript

Link to publication record in Manchester Research Explorer

\section{Citation for published version (APA):}

Janssen-Lauret, F. (2015). Meta-Ontology, Naturalism, and the Quine-Barcan Marcus Debate. In Quine and His Place in History (pp. 146-167). Palgrave Macmillan Ltd.

\section{Published in:}

Quine and His Place in History

\section{Citing this paper}

Please note that where the full-text provided on Manchester Research Explorer is the Author Accepted Manuscript or Proof version this may differ from the final Published version. If citing, it is advised that you check and use the publisher's definitive version.

\section{General rights}

Copyright and moral rights for the publications made accessible in the Research Explorer are retained by the authors and/or other copyright owners and it is a condition of accessing publications that users recognise and abide by the legal requirements associated with these rights.

\section{Takedown policy}

If you believe that this document breaches copyright please refer to the University of Manchester's Takedown Procedures [http://man.ac.uk/04Y6Bo] or contact uml.scholarlycommunications@manchester.ac.uk providing relevant details, so we can investigate your claim.

\section{OPEN ACCESS}


Meta-Ontology, Naturalism, and the Quine-Barcan Marcus Debate

Frederique Janssen-Lauret

\section{Introduction: Objects, Theories, and Epistemology}

Quine's ontological adage, 'to be is to be the value of a variable' (Quine, 1939a, p. 708; Quine, 1948, p. 32), played a pivotal role in the revival of metaphysics which gathered momentum in the second half of the twentieth century. Yet twenty-first century critics of Quine tell us he is a narrow-minded pragmatist whose naturalism consists in restricting metaphysics to the trivial and uninteresting pursuit of existence questions, especially existence questions implied by the physical sciences. Investigating Quine's views in their proper context reveals that this is a misinterpretation; his work on ontology is meant to give us a systematic way of identifying where a theory provides good reason to believe in something. He makes explicit that the influence of his pragmatism and naturalism on his meta-ontology is not to shrink the role of metaphysics and truth in our theories, or to restrict the content of available theories to the physical. It is to give a theorytranscendent criterion of where theories, scientific and philosophical, assume the existence of something: where it is posited as the occupant of some indispensable theoretical role. Modern critics try to locate Quine's naturalism where it does not belong, and as a result dismiss his view as far less interesting than it really is, as I will argue in sections 2 and 3.

Still, in sections 4-6 we see that Quine's particular form of naturalism does, after all, place some unhelpful limits on his meta-ontology. The way in which it constrains the available options is entirely different from the way twenty-first century metaphysicians imagine it to be; he is in no danger of collapsing into anti-realism, deflationism or triviality. An unfairly neglected debate shows that at least one philosophically interesting metaphysical position is, nevertheless, ruled out by Quinean meta-ontology. Ruth Barcan Marcus, whom Quine thought of as a worthy adversary, at first glance appears to be much closer to Quine than modern Carnapians or neo-Aristotelians - like him she is a realist and a naturalist, and she is also a committed nominalist. Barcan Marcus' debate with Quine has not been given the attention it deserves because their meta-ontological discussions occur along the way in the course of their better-known dispute on modality. Her decisive victory over Quine on the issue of necessary identity is now widely appreciated, and she is also beginning to be recognised as the originator of the direct reference theory of names within analytic philosophy (Barcan Marcus, 1961). But what has been missed until now is that Barcan Marcus also presents, just like Quine, a criterion of ontological commitment, complete with a characteristic canonical language of regimentation: a fully-fledged meta-ontology. Unlike Quine, she takes proper names, and not variables, to indicate ontological commitments. Close reading of the relevant texts reveals some mutual misunderstandings, leading to Barcan Marcus' views, though just as interesting as Quine's, being misinterpreted and ultimately forgotten. I now intend to revive her position as a viable meta-ontological alternative, especially attractive to contemporary adherents of her direct reference theory. Tracing the steps of their debate and reciprocal misreadings makes clear that the root of their differences is epistemology. Barcan Marcus believes in knowledge by acquaintance, codified in her canonical language by proper names. Quine does not, and accordingly bans names from his.

\section{Quine's Meta-Ontology and Its Relationship to His Naturalism}

2.1 Quine's Naturalism, His Holism, and the Continuity Between Science and Philosophy The centrality of Quine's naturalistic outlook to his meta-ontology is often misunderstood. His meta-ontological ambitions are of a broad and philosophical character: his criterion of ontological commitment provides a strategy for answering weighty questions in the intersection of logic, metaphysics, and epistemology. What kinds of entities do I have good reason to believe in, given my best theory? How to make the ontology of a theory maximally clear based on its logical form? What objects do alternative theories give others licence to believe in? Although Quine was critical of several aspects of traditional metaphysics, the historical record makes clear that his intention was to preserve what was worth saving about it. Like Quine's own ontology, what has come to be called his meta-ontology also has an explicitly naturalistic tenor: he intended to safeguard metaphysics from positivistic attacks by showing it to be continuous with natural science.

Analytic philosophers' interest in ontology faltered with the logical positivists, who thought of existence questions as uninteresting, meaningless, or misguided - trivial analytic consequences of a chosen language form at best, at worst ill-formed and not answerable at all (Carnap, 1950, p. 25). Quine cast doubt 
upon the underlying assumption that language is separable into a trivial, merely conventional part and a factual part. According to him, all statements of a theory are true or false because of a combination of fact and convention; no truths are trivially true because of language alone. Confirmation is not a matter of holding up individual theoretical statements against reality and assessing whether they match reality, if they are empirical, or whether they are just not in the business of trying to match reality. Rather, a theory, a set of sentences closed under consequence, touches upon reality as a whole, and is confirmed or disconfirmed along with everything that follows from it, including existential quantifications (Quine, 1951a, pp. 69-72). As there is no clear boundary between mere useful convention and statements that are true because of the way the world is, the dividing line between a theory's empirical claims and its logical, mathematical, or philosophical conventions dissolves: 'I see metaphysics, good and bad, as a continuation of science, good and bad' (Quine, 1988, p. 117). Existentially quantified sentences are confirmed along with others that are more closely linked to observations, because science and philosophy share a concern with what we have good reason to believe about the world. And one vital component of this concern is what kind of objects we have reason to believe the world contains based on a given theory.

\subsection{Quine on Theory-Building and Ontology Quinean ontological commitments always take the logical form}

$\Gamma_{\exists x \varphi(x)}{ }^{\urcorner}$: they contain a variable, some description containing some of the predicates of the theory that is supposed to hold of the value of that variable, and an existential quantifier to bind the variable. But why? In the late thirties to early fifties, Quine recommends 'translating' disputed existence claims into quantificational form to clarify them and remove any ambiguity. 'Monotheists and atheists now need disagree only on the truth values of statements such as [' $\left.(\exists y)(x)(x=y . \equiv \operatorname{god} x)^{\prime}\right]$, not on questions of meaningfulness' (Quine, 1940, p. 150; see also 1939, pp. 705-8). But the notion of 'translation' used here stands in need of clarification, too, as Alston (1958, pp. 12-3) and Cartwright (1954, p. 3), for instance, point out; from the late fifties onwards, perhaps under pressure from these quarters, Quine begins to develop an explanation that relies more on his philosophy of language and holist epistemology (Quine 1957-8). Quine believes that acquiring a theory, whether in infancy, or via translation, or in a scientific setting, is just to acquire a language, grown out of observations. The very early stages of theorising are composed of nothing except observation sentences, used by the budding theorist to label features in her experience: 'Tree'; 'Green'; 'Rose'; 'Red'; 'Rabbit'; 'Furry', etcetera (Quine, 1960, p. 92). From individual observations nothing else follows. All we can do with observation sentences at this stage is venture them and see what reactions we encounter. The first additions to the emerging theory are 'yes' and 'no', based on the reactions of assent and dissent. The nascent theorist is then in a position to learn to use truth-functional operators such as negation, conjunction, disjunction, and the conditional (Quine, 1960, pp. 57-59). Thus far all of the theory is empirically conditioned, directly based on experience. It is possible for theories never to develop beyond this point. Such theories remain, structurally speaking, on the level of sentential logic, and have no ontology (Quine, 1979). There are only atomic sentences and truth-functional connectives to link them.

Still, further developments have great explanatory benefits. We are able to distinguish much more fine-grained kinds of evidence if we are able to discuss and explain which observations frequently coincide and why. Our vehicle for locating patterns within the observations is the pronoun, the introduction of which turns observations into predicates, and leads the language to be enriched with further logical vocabulary: quantifiers binding the variables. Adding these resources amounts to a language with the expressive strength of first-order logic. The language learner will begin to use pronominal expressions when she notices significant intersections in her observations. The difference between intersections and mere conjunctions is marked by inserting a pronoun where observations coincide in an interesting way. 'Green. And Tree' is true in the presence of a green field and a copper beech. 'This is green and it is a tree' says something more: that green and tree persistently overlap here. The ontological vocabulary pinpoints these intersections. Reification begins when, in response to recurrent evidence of such intersections, we posit an object as a likely explanation of the pattern of overlap (Quine, 1992, p. 24). Pronouns signal an increase in explanatory capacity of a growing theory. The introduction of pronouns into the observation sentences imposes a structure on the sentences that was not there before. Previously an undivided whole, they now have a pronominal part and a predicative part. The predicative part is what is left over from the observation sentence. Observation sentences are feature-placing (cf. Strawson, 1959, p. 212), not attributive: they do not contain a word for an object and a word that attributes something to the object. The addition of variables divides the language into expressions that purport to say what there is and those that purport to say what is 
true of those beings. The former are the ontological expressions, and the latter the ideological expressions. The ideology comprises all the characteristics ascribed to the beings: what can be truly said of them and how they are related.

2.3 Naturalism, Pragmatism, Formalisation, and Realism Our best theory, couched in the clearest, least ambiguous language we can muster, will tell us exactly what it says there is: the values of its pronominal expressions. Quine is frequently criticised, though sometimes also praised (van Inwagen, 1998, pp. 235-7), for maintaining that the existential quantifier is closely related to ordinary-language 'there is'. Although Quine does occasionally say that existential quantification is just a tidied-up version of ordinary-language 'there is' or 'exists' (Quine, 1940, pp. 65-71; 1969, p. 94), at times he also expresses a much more pessimistic attitude towards the idea of extracting an ontology from ordinary-language utterances: 'Ontological concern is not a correction of a lay thought and practice; it is foreign to the lay culture, though an outgrowth of it' (Quine, 1981b, p. 9). But according to Quine all posits, naive or sophisticated, stem from the introduction of an entity on the intersection of continuous observations by means of a pronoun; if a theory lacks this quantificational form, it should be imposed upon it to work out its ontology. The theory should be regimented (Quine, 1960, ch. 5): translated - radically, following the stages outlined above - into the canonical language of first-order logic. The process of regimentation also allows us some strategies for translating out unwanted ontological commitments. Suppose we would like to deny that there are $\varphi s$, but we find ourselves making an utterance which apparently asserts or implies the existence of $\varphi s$. There are three options for regimenting our theory in such a way that it avoids commitment to $\varphi s$. First of all, we could, in Quine's words, 'take an attitude of frivolity' (Quine 1953, p. 103), or deny that the utterances $\varphi$-language occurs in are properly part of a theory at all. Second, we could eliminate: remove $\varphi$-language from our theory altogether. The third option is reduction by paraphrase, or providing a template for translating all occurrences of $\varphi$-language into statements that make no commitment to $\varphi s$, in the process producing an improved, equally explanatory but more parsimonious new theory.

As the theory progresses after its first attempts at reification, more sophisticated posits and methods are likely to ensue. Scientific standards of rigour will be formulated within the theory. It will be held up to and judged by standards of theory choice, such as simplicity, testability, and fecundity (Quine, 1955 [1966], p. 247). Its posits, too, will be re-evaluated. Questions will arise about which intersections of observations are the significant ones, the ones that call out for a posit. These questions are not answerable on purely empirical grounds (Quine, 1960, p. 51-5). As soon as we begin to reify, we introduce indeterminacy of translation, too. There is no way of pointing directly to an object. Instead they are marked out on the foci of interlocking observations, but not on all foci of interlocking observations - just the ones where we take ourselves to have the best reason to suppose an object is present as a plausible explanation of the way they intersect. How to divide the phenomena into theoretical roles that call for entities is a matter of weighing up the different options and judging them by our current best standards of theory choice: what is the simplest, most explanatory theory that best fits the data? Pragmatism, Quine-style, means that we have to keep updating our theory, as well as retain a willingness to readjust the standards by which we judge theories, though there is no God's-eye perspective from which we can assess our current theory. Any theory is such that we have to keep improving it from within, including the re-evaluation of which observations collectively amount to an explanatory role that demands the presence of an entity.

Quine has given us a template to work out, for any theory which purports to say true things about the world out there, what entities it takes that world to contain. Once all its theoretical contexts have been clarified, collected together, and closed under consequence by the process of regimentation, the existence claims will reveal what objects there are, according to this theory, and what explanatory roles they play. So why is his meta-ontology so frequently derided by twenty-first century philosophers as uninteresting, trivial, or covertly anti-realist?

\section{Quine the Metaphysician: Rebutting Some Misinterpretations of Quine As Anti-Metaphysical}

3.1 Quine the Realist Holist Quine's willingness to revise any aspect of a theory in the light of new evidence, and his unwillingness to admit a higher authority than our current best theory, should not be read as willingness to relinquish realism about truth, reference, or ontology. Recently some critics have portrayed Quine as an anti-metaphysical pragmatist (Schaffer, 2009, p. 349; Price, 2009, p. 326). But this reading is hard to square with Quine's own work. The pragmatism he commits himself to is, rather, epistemological, 
devoted to working within our best theory and improving it from the inside, and embracing porous boundaries between subject areas. Quine often expresses some measure of scepticism about old-fashioned metaphysics, but one of his meta-ontological aims is repackaging ancient debates into exciting new logical forms, the better to debate them anew. He points out that his efforts are continuous with those of earlier generations of philosophers, salvaging the kernel of truth contained within the old metaphysics and discarding what's been superseded: 'Though no champion of traditional metaphysics, I suspect that the sense in which I use this crusty old word ["ontology"] has been nuclear to its usage all along.' (Quine, 1951a, p. 66).

Price portrays Quine as committed to anti-metaphysical pragmatism and unable to make a clear distinction between truth and usefulness. In defence of this interpretation he cites only the final sentence of 'On Carnap's Views on Ontology': 'Carnap maintains that ontological questions... are questions not of fact but of choosing a convenient scheme or framework for science; and with this I agree only if the same be conceded for every scientific hypothesis' (Quine, 1951a, p. 72). In context, that reading of the sentence becomes hard to sustain. The final sentence is immediately preceded by a reference to Quine's rejection of the analytic-synthetic distinction (Quine, 1951b), countering Carnap's division of existence questions into internal (factual or analytic) and external (merely conventional) with his own argument that there are neither purely factual statements nor purely analytic or conventional statements wholly devoid of factual content (Quine, 1951a, p. 72; see also MacBride and Janssen-Lauret, forthcoming 2015, section 3). Even Carnap's own paper supports my reading: 'Quine does not acknowledge the [internal/external] distinction I emphasise above, because according to his general conception there are no sharp boundary lines between logical and factual truth, between questions of meaning and questions of fact' (Carnap, 1950, footnote 5).

Quine can frequently be found expressing the view that a useful theory is one we have good reason to hold true (a view which Price decries as 'surely a misinterpretation' of Quine (Price, 2009, footnote 4)): 'Everything to which we concede existence is a posit from the standpoint of a description of the theorybuilding process, and simultaneously real from the standpoint of the theory that is being built. Nor let us look down on the standpoint of the theory as make-believe, for we can never do better than occupy the standpoint of some theory or other, the best we can muster at the time' (Quine, 1960, p. 22; also see Quine 1981a and Ben-Menahem's discussion of Quine 1981a in her paper in this volume). Price might object that it is a further question whether this gives us good reason to believe that the values of its variables exist, since he reads Quine as a minimalist about truth (Price, 2009, p. 325). But Quine is not a minimalist about truth. He endorses disquotationalism, the Tarskian doctrine that a materially adequate truth-definition for a language $L$ which does not contain its own truth predicate must entail all T-biconditionals for that language, formulated in a stronger metalanguage which contains L's semantic vocabulary (Tarski, 1956 [1933], 188). Minimalism about truth is disquotationalism plus one additional thesis: that there is nothing more to be said about truth than is expressed by the T-biconditionals (Horwich 1990). Truth, for the minimalist, need not involve contact with objects. Quine rejects that thesis (as did Tarski before him), stating that an atomic sentence is true iff the value of its variable - that is, an object it stands for, an element of some domain - satisfies its predicate: 'Tarski's satisfaction relation has to do with objective reference, relating open sentences as it does to sequences of objects that are values of the variables.' (Quine, 1976 [1970], p. 318).

3.2 Quine Against Triviality A neighbouring misreading of Quine portrays him as an anti-metaphysical pragmatist whose meta-ontology restricts the role of metaphysics to existence questions, which are philosophically uninteresting because they follow trivially from a theory (Schaffer, 2009, p. 358). Quine himself must take some blame for this interpretation, as he asserts in the late forties that ontology is trivial to the conceptual scheme (Quine, 1948, p. 29). But this vestige of Carnapianism was soon abandoned, since it is incompatible with Quine's semantic holism. Any part of a language is potentially revisable under sufficient theoretical pressure, including its definitions, mathematics, and logical laws (Quine, 1951b, p. 40). So nothing follows trivially from anything.

Schaffer cites Hofweber (2005) puzzling over the contrast between the deep nature of metaphysical questions and the alleged triviality of existence questions, concluding that the culprit is Quinean meta-ontology (2009, p. 361). To say this is to overlook both Quine's opposition to taking existence questions as trivial in the first place and the Quinean inseparability of ontology and ideology ${ }^{1}$. A posit, for Quine, is always introduced because it fills some explanatory role phrased in terms of the theory's ideology. Every existence question which follows from some attempt at a best overall theory of the world is in fact an interesting, non-trivial consequence

1 For further details see MacBride and Janssen-Lauret, forthcoming 2015, section 3. 
of it, because there is no statement of any theory so sacrosanct that it cannot be reinterpreted in a way that yields a different set of existential consequences.

3.3 Quine's Naturalism, His Own Ontology, and His Meta-Ontology A related complaint is that Quine fails to see that while metaphysical existence questions are trivial, all non-trivial, interesting existence questions e.g. the Higgs boson - 'of course [have] nothing to do with metaphysics' (Tahko, 2011, p. 28). Contemporary metaphysicians pushing this complaint often want to return to the a priori categories of traditional Aristotelian metaphysics. Neo-Aristotelians contend that we know what an object is, and how objects in general must fit together, in advance of knowing any individual object, empirical investigation being restricted to which individual objects there are, and how they are (Lowe, 2006, p. 5). Quine certainly opposes such a sharp separation between a priori metaphysical questions and a posteriori empirical questions - but not, as the neo-Aristotelians think, because his naturalism leads him to formalise physics and resign metaphysics to the task of working out its existential consequences (Schaffer, 2009, pp. 366-7). This is to mistake Quine's own ontology for his meta-ontology. Quine's own preference for physicalism does not restrict the range of theories to which his ontological method can be applied; in fact, he is explicit from his earliest writings on meta-ontology that its interest lies in regimenting and clarifying alternative views, including more traditional philosophical ones. He mentions using quantificational form to elucidate the views of realists about propositions (Quine, 1939, p. 708), theists (Quine, 1940, p. 150), and mathematical Platonists (Quine, 1944, p. 161). And the fact that he carries on attempting to regiment and assess others' existential assumptions after his introduction of the doctrine of ontological relativity (Quine, 1968) - for instance, his worries about the criteria of identity of possible worlds (Quine, 1976) - indicates that this doctrine has not, like Schaffer says (2009, 349, 372), turned him into a deflationist about ontology. None of the contemporary arguments against Quine get him quite right; none of them indicate that he - or his contemporary followers - should give up his meta-ontology.

My interpretation of Quine reveals a much more interesting figure whose criterion of ontological commitment remains relevant, one whose naturalism inspired him to attempt to find a rigorous criterion, applicable to any theory, for having good reason to believe in something based on that theory. Quine the naturalist sought such a criterion in the practices of science, where posits are justified by their fulfilling some designated explanatory role. Quine the pragmatist applied this insight to philosophy, since he viewed the boundary between science and philosophy as porous in the first place. With this in place we will now see that, although contemporary critics are looking for flaws in all the wrong places, there is, nevertheless, a flaw in Quine's meta-ontology. He thinks that his criterion can account for all kinds of existential assumptions, but there is one significant type that he overlooks: ontological commitment via direct reference. This is because Quine's global holism is so reliant on descriptions that direct reference is difficult to make sense of.

\section{Epistemological and Metaphysical Corollaries of Quine's Meta-Ontology: Names and Identity}

4.1 All Knowledge is General Knowledge According to Quine, all theories introduce objects into their structure in the same way, and for the same purpose: they are tentatively put forward as a best explanation of a pattern of intersecting observations. Every object which belongs to the ontology of some theory, according to him, is there for a distinct explanatory reason: the theory has a need for an entity which satisfies some description $\varphi$. Our only access to objects is descriptive, by considering the object's role in our best theory. His holism implies that all of our knowledge is in principle general knowledge. So Quine's view implies a further holism-inspired thesis. We know objects only qua solutions to puzzles on how to explain the phenomena. Ontological commitments are incurred only to objects insofar as they fall under some open formula $\varphi$ of the theory: objects-qua- $\varphi$. Since we keep moving step by step towards better theories, we gradually replace our posits with better posits, too: atoms with sub-atomic particles, space with space-time, etcetera. Quine's metaontology allows us to make sense of these developments. Any object-qua- $\varphi$ is potentially dispensable. When we readjust our explanations in response to empirical developments, we drop the old posits and posit objects that answer to our new, improved descriptions.

4.2 Criteria of Identity These descriptive explanatory roles impose criteria of identity on objects. Quine's metaontology implies that all objects are subject to indiscernibility according to the predicates of the theory.

Beyond the use of predicates, there is no theoretical apparatus available to distinguish them from each other. Hypostatising a posit on the intersection of observations in the first place is a significant theoretical 
imposition for Quine, let alone a single self-identical thing being identified in different contexts. Any particular posit may be dispensable. To decide whether the existence of something is really implied by the theory, the entire wealth of theoretical resources it provides must be invoked. Criteria of identity gleaned from a complete theory are a key component of such decisions: 'Our venerable theory of the persistence and recurrence of bodies is characteristic of the use of reification in integrating our system of the world. If I were to try to decide whether the penny now in my pocket is the one that was there last week, or just another one like it, I would have to explore quite varied aspects of my overall scheme of things, so as to reconstruct the simplest, most plausible account of my interim movements, costumes, and expenditures.' (Quine, 1992, p. 24).

If an object can only be admitted into the ontology by playing some indispensable explanatory role couched in terms of the predicates of the theory, there will never be any reason to admit two objects which satisfy all and only the same predicates of that theory. There is no distinct explanatory role for the second object that the first doesn't already discharge. This implies that there is no role for identity beyond indiscernibilityaccording-to-the-theory. Quine proposes that " $\varphi x y$ " meets all the formal requirements of " $x=y$ " iff $(\forall x) \varphi x x$ and $(\forall x)(\forall y)(\varphi x y \&(\ldots x \ldots \rightarrow \ldots y \ldots))$ (Quine, 1976 [1961], p. 180, notation modernised.) He admits that his 'serviceable facsimile' for identity does not amount to the usual identity relation, the relation which partitions the domain into singleton equivalence classes (Quine, 1970, p. 64), or simply being the same thing (Quine, 1960, pp. 114-8). There may be differences between objects that the predicates of the language fail to capture. But he avers that from within the language, such differences are inexpressible; 'identification of indiscernibles' (Quine, 1953 [1950], p. 71; 1947a, p. 75) is the best we can do. Nor can we appeal to a stronger language to distinguish the two. Quine's pragmatist naturalism implies that we must always work within our best theory.

Where two posits satisfy all and only the same open formulae, they count as the same object for the purposes of that theory. We only have good reason to believe in one object per explanatory role $\varphi-$ after all, $\varphi$ is specific enough to include exact spatiotemporal coordinates and the like - so objects-qua-all-and-only-thesame- $\varphi$ s are, according to Quine, to be identified . Quinean regimented theories cannot have two distinct but indiscernible values of variables in their domains. To make the cut for being in the domain, an object has to contribute a distinct explanatory role, which means that it satisfies some open formula no other object in that domain satisfies.

4.3 Dispensing with Proper Names It appears counterintuitive that a language can speak of two distinct objects without being able to tell them apart in any way. Could we not refer to each of them by name to distinguish them? Not according to Quine, who proposes to translate away all occurrences of proper names in the process of regimentation. In the 1930s, Quine had thought of names as ontologically committing: 'To ask whether there is such an entity as roundness is ... asking whether this word is a name or a syncategorematic expression' (Quine, 1976 [1939], p. 197) 2; '“Pegasus" is not a name in the semantic sense, i.e., ... it has no designatum' (Quine, 1939, p. 703). ${ }^{3}$ He explicitly abjures their use in ontology in the forties, saying they are dispensable in favour of bound variables (Quine, 1948, p. 32). Any name $a$, he claims, can easily be transformed into a predicate $A x$ which applies only to the object formerly named $a$ if it applies to anything (Quine, 1970, pp. 25-6). 'Europe' becomes 'the unique object which europises' (Quine, 1940, p. 149). Quine returns to this argument several times over the years, but is frequently less than clear about whether ' $x$ europises' is equivalent to ' $x=$ Europe' (as he says in Quine, 1970, pp. 25-6), or to 'repars[ing]' the singular term into a general term (Quine, 1976c [1954], p. 238). The former, as Barcan Marcus objects, does not eliminate the name so much as recycle it (Barcan Marcus, $1993 b$ [1985], p. 211). The latter puts a proper name in a place where only a predicate can go - the sort of move Quine fervently deplores when it is perpetrated in reverse. Anyone who would dare put predicates (Quine, 1960, pp. 119-20) or propositions (Quine, 1943, p. 120) in name-position is apostrophised as butchering logical syntax. But whether 'europising' is acceptable or not matters very little in the end. Quine's real goal is to dispense with names in favour of a 'pat translation into a descriptive phrase ... along familiar lines' (Quine, 1948, p. 27), that is, using the ideology of the theory. His view collapses into straightforward descriptivism about names, because the requirement that every entity must be subject to a criterion of identity applies to naming too. Any

2This paper, dated 1939, remained unpublished until the first edition of The Ways of Paradox in 1966. The Erkenntnis volume it was due to appear in never materialised because of the outbreak of WWII.

3Although this paper contains the phrase 'to be is to be the value of a variable' (Quine, 1939, p. 708), it also has Quine speaking of genuine names of things being substituends for variables. 
language that meets his standards would have assigned names by means of a prior description in the first place.

To assign a name to an object we must first have singled it out by means of a descriptive phrase.

Otherwise, we could never be in a position to identify the object we just named with some object encountered in a different theoretical context. Suppose we name a river by ostension; the bearer of that name will be subject to the criterion of identity for rivers, not those for collections of water particles or spatiotemporal zones. So the ostended object must first be described as a river. '[Ostention] leaves no ambiguity as to the object of reference if the word 'river' itself is already intelligible' (Quine, 1953 [1950], p. 67). Later, when wondering whether some observed flowing body of water deserves the same appellation as the subject of our ostension, we must first make clear under what circumstances two observed entities count as the same river, i.e. are subject to the criterion of identity for rivers, or what Quine calls 'river kinship': 'the introduction of rivers as single entities, namely, processes or time-consuming objects, consists substantially in reading identity in place of river kinship.... The imputation of identity is essential, here, to fixing the reference of the ostension ' (Quine, 1953 [1950], p. 66). Quinean theories only have ontological commitments to things their ideology can describe proper names themselves cannot introduce an ontological commitment to an entity. A theory cannot be committed to an individual qua individual, independently of how it is described. But this is precisely the kind of ontological commitment that Quine's interlocutor Ruth Barcan Marcus advocates.

\section{Barcan Marcus' Name-Based Meta-Ontology}

\subsection{Barcan Marcus' Name-Based Criterion of Ontological Commitment Like Quine, Barcan Marcus is} naturalistically inclined, professing a distaste for abstract objects. But their meta-ontologies are diametrically opposed, because of a difference in epistemology (Barcan Marcus, 1978, pp. 358-9). Although Barcan Marcus shares Quine's affinity for physical objects and distaste for propositions, properties, and other abstracta ${ }^{4}$ like numbers, sets, and properties, and an unwillingness to ascribe referential status to predicates and logical operators, her nominalism has a very different epistemological motivation: she is a foundationalist. She takes as a point of departure the idea that when we interact with the world, we encounter individuals, which we come to know by acquaintance. Our minds reach out to concrete objects like other people, organisms, artefacts, and lifeless matter, and our command of names allows us to stick a label on any such concrete object: a tag (Barcan Marcus, 1961, p. 310). Tags' semantic function is to stand for things, while other forms of language - predicates, logical operators, mathematical discourse, the language of moments in time or events, talk of propositions, and fiction (Barcan Marcus, 1972) - have no subject matter for them to refer to. So they are mere language, a flatus vocis. She expresses puzzlement at Quine's decision to let variables 'bear the burden of reference', preferring 'alternative analyses for locating references in an interpreted language ... names and their relation to nameable objects' (Barcan Marcus, 1978, p. 359).

Barcan Marcus can be read as proposing a fully-fledged criterion of ontological commitment with its own attendant canonical language of regimentation to complement it, summed up as a slogan to rival Quine's: 'to be is to be the referent of a tag'. For Barcan Marcus, it is not variables, but directly referential proper names, that betoken ontological commitment. Not every apparent proper name in English will go into her regimented language as a tag. Her epistemology implies that concrete individuals can be assigned tags, but we have no good reason to believe in abstracta and therefore our predicates, logical constants, numerical terms, propositional locutions, abstract nouns, and fictional empty names are syncategorematic, and will be rendered as non-referring expressions in her canonical language.

Existence claims, and the variables contained within them, are not ontologically committing for Barcan Marcus. She combines her tag theory of reference with a substitutional interpretation of the quantifiers. Where Quine attempted to reduce apparently ontologically committing uses of proper names to variables, Barcan Marcus' solution is an exact mirror image of Quine's: quantifiers are reduced to names. Quantificational truth is explained in terms of substitution instances. Variables are relieved of the burden of reference; they are not by themselves ontologically committing, because they do not have values. They are placeholders for substituends. She believes substitutional quantification to be a better match for her nominalism and a better rendition of many of our ordinary-language statements: 'There are, even in ordinary use, quantifier phrases that seem to be ontologically more neutral, as in: "It is sometimes the case that

4 The later Quine stopped calling himself a nominalist because he felt compelled to allow quantification over sets, insofar as it is indispensable to physics (Quine, 1981b). His views remained nominalistic in the sense of opposition to universals. 
species and kinds are, in the course of evolution, extinguished". It does not seem to me that the presence there of a quantifier forces an ontology of kinds or species. If the case is to be made for reference of kind terms, it would have to be made, as for proper names, independently. Translation into a substitutional language does not force the ontology. Such usage remains, literally and until the case for reference can be made, à façon de parler.' (Barcan Marcus, 1978, p. 359).

\subsection{Barcan Marcus' Canonical Language of Regimentation It is fairly easy to see what Barcan Marcus'} canonical language should look like; one proposal of such a language was sketched by Dunn and Belnap (Dunn and Belnap, 1968). Its lexicon would at minimum contain a finite or denumerable set of constants, a finite or denumerable set of predicates, a denumerable set of variables, the usual truth-functional operators (for instance, ' $\neg$ ' and ' $\&$ '), the quantifiers (' $\forall$ ', ' $\exists$ '), and an identity predicate. There would also be a category of singular terms that are not constants, never deployed as tags. Barcan Marcus further allows for lexical items like modal operators, second-order variables, or set-theoretic vocabulary, none of which are ontologically committing (Barcan Marcus, 1972). The standard syntax applies, but it must stipulate that only constants or variables can flank the identity sign, because only individuals are self-identical. The non-tag singular terms can be concatenated with other predicates, but not identity. The interpretation maps the constants to the individuals of a domain, where every constant is a tag: each is assigned to an element and each element has a name. That function may be one-one, but need not be (Barcan Marcus, 1961, pp. 309-311).

Atomic sentences consisting of a predicate plus a tag are true when the bearer of the tag satisfies the predicate, false otherwise. All atomic sentences of the form ' $a=a$ ' are true. Those of the form ' $a=b^{\prime}$ are true iff the bearer of ' $a$ ' is the same individual as the bearer of ' $b$ ', false otherwise. All other atomic sentences, including those with non-tag singular terms, are assigned truth values by the interpretation. All connectives as well as the substitutional quantifiers can be assigned true or false in terms of truth alone: ' $\neg p^{\prime}$ is true iff ' $p$ ' is false, ' $p \& q$ ' is true iff ' $p$ ' is true and ' $q$ ' is true, and $\forall x F x^{\prime}$ ' is true iff ' $F t^{\prime}$ is true for all terms ' $t$ '; ' $\exists x F x^{\prime}$ ' is true iff ' $F t^{\prime}$ ' is true for at least one term ' $t$ ', (Dunn and Belnap, 1968). All substitution instances which contain non-tag singular terms as substituends - for Barcan Marcus, this would include fictional terms, higher-order terms, and terms for mere possibilia, for example - will have been assigned truth values by the interpretation quite independently of any ontological considerations, and have no bearing on the ontology. What, then, is the theory's ontology? All and only the things it makes direct reference to: all the referents of its tags. The quantifiers are ontologically inert. Barcan Marcus' conception of identity as old-fashioned sameness of thing plus her idea that direct reference commits the speaker to the existence of an object allows us to introduce ontological commitments incurred via acquaintance rather than descriptively.

\section{Barcan Marcus Wins on Names, Quine on Quantifiers}

Quine considered Barcan Marcus a formidable opponent he enjoyed crossing swords with ${ }^{5}$ and regularly credits her with significant changes of heart. His favourable review (Quine, 1947b) of Barcan's quantified modal logic (Barcan 1947) spelled the end of his previous position that modal logic was invariably a use-mention confusion got out of hand, although he carried on believing for a few more years that modal operators are to be analysed away in terms of analyticity (Quine, 1947c, p. 45; Quine, 1951b, p. 22). Undeterred, Barcan mounted a strong campaign against Quine's anti-modal arguments, demonstrating how his 'number of planets' argument (Quine, 1953) is invalid in her QS4 (Barcan Marcus, 1961, pp. 313-4) and how his 'mathematical cyclist' argument $^{6}$ (Quine, 1960, p. 199) does not entail the conclusion he thinks it does, that modal logics must divide attributes into the essential and the accidental (Barcan Marcus, 1967). Quine kept conceding ground to Barcan Marcus on modal logic (a catalogue of her victories is detailed in Barcan Marcus, 1990). On the issue of substitutional quantification, too, she gradually convinced him that her interpretation was a respectable alternative to his. After discussions with Barcan Marcus he began to understand that her interpretation is not incoherent, but a result of dissociating the quantifier from ontological commitment. He subsequently describes it

5 Barcan Marcus also enjoyed this pastime in a literal sense; see Hochberg (2014) for his account of her challenging him to a duel in a castle.

6 Quine continued to maintain the anti-essentialist conclusion that although it makes some sense, in context, to say that rationality is essential to mathematicians or two-leggedness to cyclists, it makes no sense to say of an individual, independently of how that individual is described, that he or she is necessarily rational or bipedal. This argument is also deeply interwoven with Quine's global holism, and with that in mind the conclusion is to some extent defensible. See MacBride and Janssen-Lauret (forthcoming 2015). 
as an intelligible, though 'deviant', reading of quantification (Quine, 1970, pp. 89-90), even providing an alternative Tarskian truth definition for it (Quine, 1976 [1970]). But Quine does not seem to have fully appreciated the epistemological dimension of Barcan Marcus' views. He never takes her endorsement of direct reference to heart, claiming the distinction between names as tags and descriptions is 'a red herring' (Barcan Marcus, 1993a, p. 34).

This misunderstanding, plus his failure to realise that Barcan Marcus has a criterion of ontological commitment and canonical language to rival his own, means that Quine never directly addressed her arguments for the ontologically committing status of names. Barcan Marcus' direct reference theory of proper names (Barcan Marcus 1961), brought into the philosophical mainstream by Kripke (Kripke 1980), now has numerous adherents. Staunch direct reference theories might prefer to give up Quinean meta-ontology if it is as inextricably linked to his descriptivism as would appear - so ought they to embrace Barcanian ontological commitment instead?

Quine does offer some explicit arguments against having proper names as part of the canonical language, although they draw mostly upon the philosophy of logic rather than epistemology. None of them are especially effective against Barcan Marcus. Quine's first concern is to avoid the Meinongian inference that using a fictional name, like 'Pegasus', implies an existence claim by existential generalisation (Quine, 1948, p. 26). But in Barcan Marcus' canonical language, what she calls 'E-generalisation' does not entail that something exists (Barcan Marcus, 1978, p. 358); only the use of a tag does. Since 'Pegasus' is not a tag, Quine's problem does not arise. Secondly, he contends that the use of a name need not incur an ontological commitment, because it can be coherently denied that the name-like phrase is a name if it fails to denote (Quine, 1951a, p. 67). But this does not refute Barcan Marcus, who does not believe that any use of an apparent name trivially implies a commitment to a bearer - after all, it is coherent to translate an apparently name-like expression into the canonical language as a non-tag term or a description, if it fails to fulfil the characteristic name-like function of singling out an object directly. The problem is not with names, but with the assumption that anything follows trivially from anything, which, we saw above, anyway relies on a dubious analytic-synthetic dichotomy. Lastly, Quine objects that omitting names simplifies logical syntax, allowing for a single category of singular terms. A language with both constants and variables must have two such categories, since they have different syntactic properties. A variable can be appended to a quantifier symbol in order to bind all of its subsequent occurrences in a subformula; a name cannot (Quine, 1970, p. 26). This is true enough, but not decisive. Quine himself advocates trading simplicity of syntax for greater expressive power when he justifies embracing a firstorder language over one with the structure of sentential logic. A bifurcated category of singular terms which bestows other theoretical advantages upon a language constitutes a good reason to opt for a more complex syntax.

And there are some theoretical advantages to ontologically committing proper names, principally the option to distinguish names from definite descriptions. On this point, too, Barcan Marcus and Quine continued to talk past each other over the course of several interactions. Barcan Marcus misunderstood Quine just as much as he did her, apparently taking him to be merely confused: 'It is a curious fact that Quine, who leaned on the theory of descriptions in "On What There Is" as a solution to puzzles about nonreferring singular terms, failed to see its effectiveness in dispelling his apparent puzzles about substitutivity in modal contexts' (Barcan Marcus 1993b [1985], p. 192). This curious fact is accounted for once we see that on Quine's view, names can never rise above the level of descriptions, nor identity above the level of indiscernibility. Recall that Quinean commitments are aways made to objects-qua- $\varphi$, objects insofar as they satisfy some open formula of the theory. So ontological commitment to an object $a$ must be regimented instead as commitment to the $\varphi$. As a result Quine cannot admit any theoretically salient distinction between ' $a=b$ ' and 'the $\varphi$ satisfies exactly the same open formulae as the $\psi$ '. Barcan Marcus would counter that ' $a$ ' and 'the $\varphi$ ' are very different in both meaning and semantic function: ' $a=b$ ' is, if true, a necessary truth, even a logical truth, because it is arrived at by substituting co-referential terms in the logical truth ' $a=a^{\prime}$ (Barcan Marcus 1961, p. 308). She would also object that satisfying exactly the same open formulae is not a sufficient condition for identity. Descriptions cannot be 'strongly equated' with each other, the way directly referential expressions such as names and variables can, but only weakly (Barcan Marcus, 1961, p. 310-1). Barcan Marcus appears to have overlooked that Quine-style ontological commitment implies descriptivism and a weak imitation of identity. She may initially have been misled by the fact that he repeatedly tries to shelve, in his reply to her and subsequent discussion, the question of direct reference as irrelevant to modality (1976e [1961] p. 181-2), into thinking that he accepted direct reference but failed to see its pertinence to the issue. Quine's use of 'socratising'-style predicates may also have led her down this path. She 
reads them as having the deep logical structure of ' $x$ = Socrates', with identity in her own, strong sense, and 'Socrates' occurring as a genuine proper name. She opposes this move on the grounds that 'being identical to Socrates is ... not a general property [because such] properties ... have components that refer to individuals directly' (Barcan Marcus 1993a p. 231 footnote 49). ${ }^{7}$ These kinds of predicates covertly rely on the semantic force of direct reference in order to be meaningful at all. Therefore '[s]uch devices do not eliminate the name, they recycle it' (Barcan Marcus, 1993b [1985], pp. 211-2).

A name-based criterion of ontological commitment is more congenial to modern direct reference theorists, of which there are many, than Quine's attitude towards names. Still, Quine has the advantage over Barcan Marcus in one respect. Because her substitutional quantifier always requires terms as substituends for its truth conditions, there can be at most as many things quantified over as there are names. Names, being discrete, listable items, must be denumerable. Compared to the objectual quantifier, Barcan Marcus' quantifier is simultaneously too strong and too weak. Too strong, because if the substitutional quantifier is such that ' $\forall x F x^{\prime}$ is equivalent to ' $\mathrm{Fa}_{0} \& \mathrm{Fa}_{1} \& \mathrm{Fa}_{2} \ldots$..', with a denumerable infinity of names ' $\mathrm{a}_{0}{ }^{\prime}, \mathrm{a}_{1}{ }^{\prime}, \mathrm{a}_{2}{ }^{\prime}$ '... that ' $F x^{\prime}$ can be concatenated with, the quantifier amounts to an $\omega$-rule. This would compel the substitutionalist to reject compactness and thereby the traditional classical consequence relation (Dunn and Belnap, 1968, p. 180; Shapiro, 2000, § 9.1.4.). Too weak, because since the number of names cannot be more than denumerably infinite, it cannot quantify over non-denumerable domains. But there are plausible ontologies with nondenumerable cardinalities: for instance, those that quantify over the natural numbers, or non-quantised spacetime points. Barcan Marcus' nominalist sympathies, rooted as they are in a strongly foundationalist epistemology of the encounterability of individuals through acquaintance, lead her to profess uncertainty about infinities, even of the denumerable kind (Barcan Marcus 1993a [1961], p. 27; 1978, pp. 360-1). Both criteria have a substantial advantage in one regard, and a substantial disadvantage in the other; Barcan Marcus' tag criterion best accommodates direct reference theorists; Quine's quantificational criterion is preferable for proponents of objectual quantification over non-denumerable domains.

\section{Acknowledgements}

Thanks are due to audiences at the Universities of Campinas, Glasgow, McMaster, and Rome La Sapienza, and also to the people who attended my postgraduate seminar Logical Form and Ontology at the University of Campinas in 2014. I am also grateful to Gary Ebbs, Jane Heal, Fraser MacBride, and Peter Sullivan for discussion. This research was supported by a Capes Postdoctoral Research Fellowship Grant.

\section{Bibliography}

R. Barcan (1947) 'The Identity of Individuals in a Strict Functional Calculus of Second Order.' The Journal of Symbolic Logic, 12(1): 12-15.

R. Barcan Marcus (1961) 'Modalities and Intensional Languages', Synthese, 13(4): 302-322.

R. Barcan Marcus (1967) 'Essentialism in Modal Logic', Noûs, 1(1): 90-96.

R. Barcan Marcus (1972) 'Quantification and Ontology', Noûs, 5(3): 187-202.

R. Barcan Marcus (1978) 'Nominalism and the Substitutional Quantifier', The Monist, 61(3): 351-62.

R. Barcan Marcus (1990) 'A Backward Look at Quine's Animadversions on Modalities', in R. Barrett and R. Gibson (eds.), Perspectives on Quine, Blackwell, Oxford, 1990, 230-243. Reprinted in Modalities (New York: Oxford University Press).

R. Barcan Marcus (1993a [1961]) 'Modalities and Intensional Languages Appendix 1A: Discussion', in Modalities (New York: Oxford University Press).

R. Barcan Marcus (1993b [1985]) 'Possibilia and Possible Worlds', in Modalities (New York: Oxford

7See also (Barcan Marcus, 1967). 
11 “Meta-Ontology, Naturalism, and the Quine-Barcan Marcus Debate” by F.M. Janssen-Lauret, in Quine and His Place in History

University Press).

Y. Ben-Menahem (2015) 'The Web and the Tree: Quine and James on the Growth of Knowledge', this volume.

R. Carnap (1950) 'Empricism, Semantics and Ontology', Revue Internationale de Philosophie, 4: 20-40.

M. Dunn and N. Belnap (1968) 'The Substitution Interpretation of the Quantifiers', Noûs, 2(2): 177-185.

H. Hochberg (2014) 'Some Things Recalled', Dialectica, 68(2), 171-182.

T. Hofweber (2005) 'A Puzzle about Ontology', Nô̂s, 39: 256-283.

P. Horwich (1990) Truth (Oxford: Basil Blackwell).

S. Kripke (1980) Naming and Necessity, Oxford University Press.

E.J. Lowe (2006) The Four-Category Ontology (Oxford: Clarendon Press).

F. MacBride and F. Janssen-Lauret, (forthcoming 2015), 'Meta-Ontology, Epistemology \& Essence: On the Empirical Deduction of the Categories', The Monist, 98(3).

H. Price (2009) 'Metaphysics after Carnap: The ghost who walks?' in D.J. Chalmers, D. Manley, and R. Wasserman (eds.), Metametaphysics, Oxford University Press, 320--46.

W.V. Quine (1939a) 'Designation and Existence', The Journal of Philosophy, 39: 701-709.

W.V. Quine (1943) 'Notes on Existence and Necessity', The Journal of Philosophy, 40: 113-127.

W.V. Quine (1944), O Sentido da Nova Logica, Martins, Sao Paulo.

W.V. Quine (1947a) 'On Universals', The Journal of Symbolic Logic, 12(3): 74-84.

W.V. Quine (1947b) 'Review of "The Identity of Individuals in a Strict Functional Calculus of Second Order" by Ruth C. Barcan', The Journal of Symbolic Logic, 12(3): 95-96.

W.V. Quine (1947c) 'The Problem of Interpreting Modal Logic', The Journal of Symbolic Logic, 12(2): 4348.

W.V. Quine (1951a) 'On Carnap's Views on Ontology', Philosophical Studies, 2: 65-72.

W.V. Quine (1951b), 'Two Dogmas of Empiricism', The Philosophical Review, 60: 20-43.

W.V. Quine (1953) 'Reference and Modality'. In W.V. Quine (1953), From a Logical Point of View. Harvard University Press, Cambridge, Mass., 139-59.

W.V. Quine (1953 [1950]) 'Identity, Ostension, and Hypostasis' in From a Logical Point of View (Cambridge, Mass.: Harvard University Press)

W.V. Quine (1957-8) 'Speaking of Objects', Proceedings and Addresses of the American Philosophical Association, 31: 5-22.

W.V. Quine (1960) Word and Object (Cambridge, Mass: MIT Press).

W.V. Quine (1968) 'Ontological Relativity', The Journal of Philosophy, 65(7): 185-212.

W.V. Quine (1969) 'Existence and quantification' in Ontological Relativity and Other Essays (New York:

Columbia University Press).

W.V. Quine (1970) Philosophy of Logic (Englewood Cliffs: Prentice-Hall).

W.V. Quine (1976a) 'Worlds Away', The Journal of Philosophy, 73(22): 859-63.

W.V. Quine (1976b [1939]) 'A Logistical Approach to the Ontological Problem' in The Ways of Paradox, second edn (Cambridge, Mass.: Harvard University Press). 
W.V. Quine (1976c [1954]) 'The Scope and Language of Science', in The Ways of Paradox, second edn (Cambridge, Mass.: Harvard University Press).

W.V. Quine (1976d [1955]) 'Posits and Reality', in The Ways of Paradox, second edn (Cambridge, Mass.: Harvard University Press).

W.V. Quine (1976e [1961]) 'Reply to Professor Marcus', in The Ways of Paradox, second edn (Cambridge, Mass.: Harvard University Press).

W.V. Quine (1976f [1970]) 'Truth and Disquotation', in The Ways of Paradox, second edn (Cambridge, Mass.: Harvard University Press).

W.V. Quine (1979) 'On not learning to quantify', The Journal of Philosophy, 76: 429-430.

W.V. Quine (1981a) 'The Pragmatists' Place in Empiricism' in R. J. Mulvaney \& P.M. Zeltner (eds.) Pragmatism: Its Sources and Prospects (University of South Carolina Press).

W.V. Quine (1981b) 'Things and Their Place in Theories' in Theories and Things, (Cambridge, Mass., Harvard University Press)

W.V. Quine (1988) 'Comment on Agassi's remarks', Zeitschrift für allgemeine Wissenschaftstheorie / Journal for General Philosophy of Science, 19(2): 117-118.

W.V. Quine (1992) Pursuit of Truth, revised edn (Cambridge, Mass., Harvard University Press).

J. Schaffer (2009) 'On what grounds what' in D.J. Chalmers, D. Manley, and R. Wasserman (eds.), Metametaphysics (Oxford: Oxford University Press).

S. Shapiro (2000) Foundations without Foundationalism, second edn (Oxford: Oxford University Press).

T. Tahko (2011) 'In defence of Aristotelian metaphysics' in Contemporary Aristotelian Metaphysics (Cambridge: Cambridge University Press).

A. Tarski, (1956 [1933]) 'The Concept of Truth in Formalised Languages', in Logic, Semantics, Metamathematics (Oxford: Clarendon Press).

P. van Inwagen (1998) 'Meta-ontology', Erkenntnis, 48:233-250. 